\title{
EUROPE'S DRAGONFLIES
}

A field guide to the damselflies and dragonflies

Dave Smallshire and Andy Swash

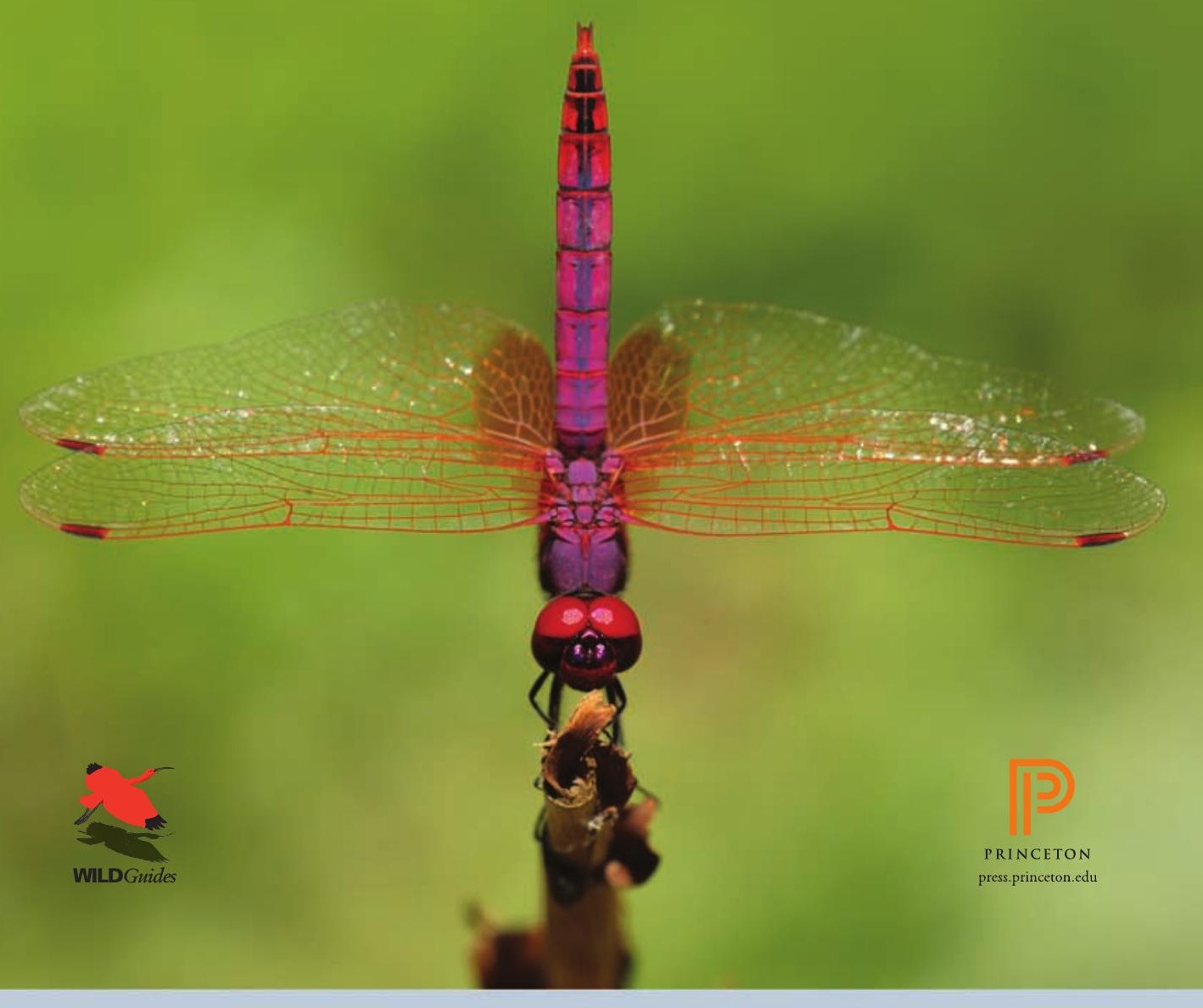


Published by Princeton University Press,

41 William Street, Princeton, New Jersey 08540

In the United Kingdom: Princeton University Press, 6 Oxford Street, Woodstock, Oxfordshire OX20 1TR

press.princeton.edu

Requests for permission to reproduce material from this work should be sent to Permissions, Princeton University Press

First published 2020

Copyright (c) 2020 by Princeton University Press

Digital artwork, maps and illustrations copyright @ 2020 by Robert Still

Copyright in the photographs remains with the individual photographers.

All rights reserved. No part of this publication may be reproduced, stored in a retrieval system, or transmitted, in any form or by any means, electronic, mechanical, photocopying, recording, or otherwise, without the prior permission of the publishers.

British Library Cataloging-in-Publication Data is available

Library of Congress Control Number 2020931167

ISBN 978-0-691-16895-1

Production and design by WILDGuides Ltd., Old Basing, Hampshire UK.

Printed in Italy 